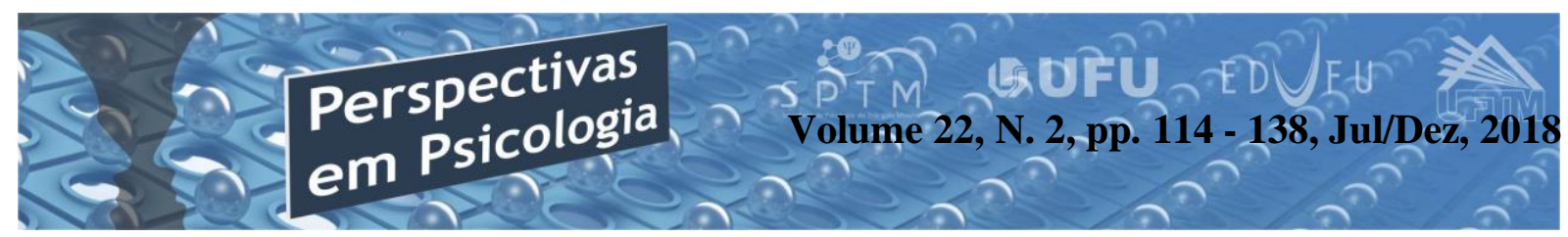

\title{
ÁLCOOL COMO SINTOMA: HISTÓRIAS DE VIDA DE DEPENDENTES
}

\author{
Márcio Kobayashi \\ (UNIFAAT - Centro Universitário - Atibaia - SP) \\ Marjorie C.R. Silva \\ (Centro Universitário Salesiano de São Paulo - São Paulo - SP) \\ Geraldo A. Fiamenghi-Jr \\ (UNIFAAT - Centro Universitário - Atibaia - SP)
}

\begin{abstract}
Resumo
Esta pesquisa objetivou investigar a relação entre dependência do álcool e história de vida num grupo de sete homens, com idades entre 42 a 70 anos, frequentadores, há mais de dois anos, do AA, numa cidade do interior de São Paulo. Apresentou-se aos participantes uma Narrativa Interativa inacabada, elaborada pelos pesquisadores, sobre o tema do alcoolismo, que os participantes completavam por escrito, além de entrevistas gravadas. Foram definidos sete campos de sentido a partir da interpretação das narrativas e das entrevistas, articulados teoricamente com a literatura psicanalítica. Observou-se que cada sujeito possui histórias singulares quanto ao início e permanência no uso do álcool; a importância da fala do sujeito e seu poder curativo; a necessidade de reparação pelos danos causados à própria vida e/ou no ambiente familiar e a identificação dos sujeitos dependentes com o grupo AA, no qual buscam ajuda para recuperação.
\end{abstract}

Palavras-chave: alcoolismo; dependência; psicanálise; família.

\begin{abstract}
Alcohol as symptom: Dependents' life stories

This research aimed to investigate the relationship between alcohol's dependence and life stories of a group of 7 men, aged between 42 to 70 years, participating for more than two years in a AA group, in a country town of São Paulo. Participants completed an unfinished Interactive Narrative developed by the researchers, as well as a recorded interview. Seven domains of meaning were identified stemming from the narratives' interpretation as well as the interviews and linked with Psychoanalysis. It was observed that each subject has singular stories as the beginning and permanence using alcohol; the importance of the subject's speech and its healing power; the need for reparation of damages caused to own life and/or family and the identification of dependent subjects to AA group, inside where they rely for recovery.
\end{abstract}

Keywords: alcoholism; dependence; Psychoanalysis; family.

I. Introdução

O álcool é uma substância que causa dependência. No mundo, essa dependência 
preocupa enormemente os sistemas de saúde. Estima-se o número de dependentes entre $10 \%$ e $15 \%$ da população mundial. Só no Estado de São Paulo, pelo menos 1 milhão de pessoas sofrem desse mal (Ministério da Saúde, 2015). O alcoolismo é considerado como doença apenas quando o usuário apresenta tolerância, abstinência e perda do controle (Gigliotti \& Bessa, 2004), ou seja, necessita de doses cada vez maiores de álcool para que obtenha o mesmo efeito, ou diminuição do efeito do álcool com as doses tomadas anteriormente e pela síndrome de abstinência, quando da diminuição, ou suspensão do consumo etílico. Para Ribeiro (2009), no campo psicanalítico, entende-se o uso das drogas como uma possível resposta do sujeito que fica à mercê dos costumes da sociedade e da cultura, assim como da constituição psíquica particular, que responderá de modo diverso aos apelos sociais. Segundo Freud (1930/1997), o desenvolvimento psíquico e social torna-se difícil e árduo. Para suportar todo esse fardo, utiliza-se de medidas paliativas, derivativos poderosos, as satisfações substitutivas e as substâncias tóxicas.

Os primeiros trabalhos psicanalíticos desenvolvidos a respeito das adições surgiram a partir da teoria freudiana das pulsões. Uma vertente sobre o estudo das adições foi o foco no estatuto do objetodroga, tratando de interrogar a natureza do vínculo que une o sujeito ao objeto da adição, ou seja, a natureza de um vínculo tão estabelecido que comprometa sua vida emocional (Gurfinkel, 2007). Outra dimensão a ser compreendida do fenômeno aditivo é o modelo do fetichismo. Para Freud (1927/1976b), o sujeito fetichista apresenta uma distorção em sua conduta sexual, com uma fixação a um objeto. Nas adições, em geral, observa-se uma fixação exacerbada a um objeto, sendo buscado como única fonte de prazer para o sujeito, tornando uma espécie de objeto-fetiche. Assim, o objeto torna-se coisa em si, como estratégia de defesa perante a uma ameaça de aniquilamento do sujeito.

Para Winnicott (2000), a relação com o objeto externo fornece a base de sustentação para a área da ilusão; quando essa relação com os objetos ameaça esmaecer para o sujeito, os objetos são investidos com ênfase com o objetivo de preservar o self do sujeito. Stacechen e Bento (2008) consideram que o álcool surge como um objeto essencial, mas não como única finalidade de refúgio para o dependente. O dependente faz uso do álcool para poder lidar com sentimentos que são angustiantes e difíceis, tendo o álcool como recurso para dar fuga a esses sentimentos e tendo como finalidade reduzir angústias através do seu uso. Outro aspecto significativo é a exaltação do eu, de modo 
narcisista, também promovido pela sociedade hoje (Freud, 1921/1976).

A bebida aparece na vida de um sujeito como um objeto de defesa para enfrentar a realidade, o passaporte de entrada da pessoa num plano diferente de seu cotidiano, já apontado por Freud (1930/1996). O alcoolismo, sendo crônico, altera o comportamento, modificando o ambiente familiar, social, o funcionamento pessoal desse dependente. $\mathrm{O}$ alcoolista tem dificuldade para admitir que faz uso abusivo do álcool, acredita poder interrompê-lo a qualquer momento e não percebe as dificuldades do consumo excessivo (Chagas, 2008). As propriedades do álcool provocarão mudanças nas atitudes, muitas vezes agressivas, no sujeito dependente, mas o problema está na maneira como irá conduzir o perigo e a sua capacidade de causar danos (Freud, 1930/1996).

Segundo Galvão (2001), durante o momento de plenitude, o álcool leva o sujeito que ingeriu a um encontro com o objeto perdido ou faltante, pois nesse momento nada falta para ele, retornando ao prazer primitivo com a mãe. $\mathrm{O}$ dependente de álcool encontra, na bebida, o objeto que preenche essa falta, tendo um gozo pleno até o fim do efeito da substância no organismo. Em seguida, surge o mal-estar, da volta para a realidade e, para recobrar o prazer e gozo constantes, ele anseia por ingerir mais álcool, retomando o circuito alcoólico, ou seja, álcool $=$ mal-estar $=$ mais álcool. O alcoolismo possivelmente tenta corrigir uma castração, já que não houve limites. Há uma tentativa de valer um gozo pelo Outro, ou seja, um gozo que não se relaciona com a castração, um gozo sem limite (Galvão, 2001).

$\mathrm{Na}$ psicanálise, a tendência à repetição se apresenta no inconsciente, relacionada à falta. Através da repetição, o sujeito castrado tende a controlar a ausência. É próprio da repetição o fracasso da tentativa de reencontrar o perdido. É importante notar a dupla função da repetição; de um lado, buscar pelo perdido e pelo gozo, e por outro, a cada vez que há esse movimento, reeditar o limite do gozo. Portanto, a repetição está no discurso e não no comportamento que surge (Gianesi, 2005).

A irmandade Alcoólicos Anônimos (AA) existe há 73 anos no mundo e há 62 anos no Brasil. No mundo, atualmente, existem 100.000 grupos do AA, espalhados por 170 países, com, aproximadamente 2 milhões de membros. No Brasil, a estimativa é de 4.900 grupos de AA. Esses dados revelam com que facilidade o AA se faz presente em diferentes países, sendo capaz de se infiltrar em diversas culturas e classes sociais (Reis, 2007). O problema do alcoolismo é visível na sociedade brasileira e ainda são raros os tratamentos tão eficazes 
e de baixo custo, como o modelo usado pelo AA. Contudo, não existem dados que comprovem a eficácia do programa de recuperação proposto pelo AA, ou seja, sobre a mensuração de pessoas que se recuperam, ou quantas pessoas recaem (Ribeiro, Cunha \& Azarias, 2011). Uma leitura psicanalítica de grupos como o dos Alcoólicos Anônimos pode compreendê-los como uma forma de tratamento institucional, que não tem como propósito abrir espaço para uma escuta psicanalítica. Porém, tal mecanismo permite um olhar psicanalítico, visto que convoca o sujeito para uma relação entre pares, ao se identificar com os relatos e histórias partilhadas no grupo.

A clínica psicanalítica não se ocupa em olhar o alcoolismo como doença, ou buscar alguma classificação nosológica do sujeito alcoolista, pois volta seu olhar para o sujeito em si mesmo, vendo o alcoolismo como sintoma e não como rótulo. É possível, a partir da escuta psicanalítica, perceber o lugar que a dependência do álcool ocupa na subjetividade do paciente. O grupo não elimina os aspectos pessoais e únicos dos participantes, mas pode favorecer que eles apareçam, quando há ambiente de confiança e respeito. Somente uma escuta atenta do sujeito pode levar ao conhecimento das verdadeiras causas da sua dependência (Nogueira, 2006).
Freud (1921/1976) explica que há um contraste entre psicologia individual e de grupo pois, na individual, existe uma relação com um único sujeito, que explora os caminhos e tenta encontrar satisfação para seus impulsos instintuais. Já o grupo psicológico é um ser provisório, em que há uma combinação heterogênea por um curto período de tempo. Pode-se pensar que o laço existente entre os membros de um grupo é oriundo de uma identificação bemsucedida, sendo reconhecida essa qualidade de identificação em um líder (Freud, 1921/1976). No contexto terapêutico grupal, as contribuições de um paciente ao processo terapêutico de outro são estimuladas, com exemplos, confrontandoo, ou mesmo dando interpretações possíveis, permitindo a manifestação da criatividade. Assim, a competição pode se tornar fraternidade e o apoio e a solidariedade mútua, elementos terapêuticos importantes numa situação grupal (Mello Filho, 2001). Assim, O objetivo geral desse estudo foi investigar a relação entre dependência química e história de vida, nos sujeitos dependentes de álcool, em um grupo de participantes dos AA.

\section{Método}

\subsection{Participantes}


Participaram dessa pesquisa sete homens, com idades variando entre 42 a 70 anos, todos frequentadores, há mais de dois anos, do AA, numa cidade do interior de São Paulo.

\subsection{Instrumentos}

Foram utilizadas narrativas interativas (Granato, Corbett \& AielloVaisberg, 2011), com adaptação, consistindo em apresentar a cada participante individualmente, uma mesma narrativa elaborada pelos pesquisadores, versando sobre a temática. Uma vez que se encontrava inacabada, o participante era chamado a engajar-se na construção da narrativa, finalizando-a como um parceiro.

Para esta pesquisa, foi proposta a seguinte história:

João era um adolescente, filho único e morava com seus pais. Ele tinha vários amigos, mas não era um bom aluno. Seu relacionamento com seu pai era tumultuado, porque seu pai bebia todos os dias e era agressivo com a mãe e com ele. Já sua mãe era compreensiva, afetuosa, e carinhosa, diferente de seu pai que, mesmo sóbrio, não lhe dava atenção. Nessa relação com a mãe, João se sentia mais seguro. Quando completou 15 anos João perdeu sua mãe, que morreu em decorrência de um câncer no fígado. Ele sofreu muito com essa perda, e morar com o pai foi se tornando mais difícil. João foi ficando mais calado, menos sociável e mais distante dos seus amigos. Foi então que...

\subsection{Procedimentos}

Após a aprovação do projeto pelo Comitê de Ética e Pesquisa com Seres Humanos, os participantes foram contatados em visita aos seus encontros, convidados a colaborar na pesquisa, após entendimento com seus coordenadores. Os participantes que optaram por colaborar com este estudo assinaram um Termo de Consentimento Livre e Esclarecido.

Os dados foram coletados individualmente no espaço da própria instituição, em horário diferente do horário das reuniões ordinárias. Os participantes receberam uma caneta e uma folha, contendo a narrativa iniciada, para que completassem uma história que versa sobre o tema alcoolismo, após a leitura conjunta com os aplicadores. Se algum participante julgasse conveniente, poderia fazer sua narrativa oralmente, e as anotações ficariam ao encargo do aplicador, em outro horário a combinar. As estórias foram terminadas em um período de, aproximadamente, duas horas. Assim que terminaram, os participantes foram convidados a refletir sobre a experiência realizada e a narrativa produzida. Estas entrevistas posteriores foram gravadas. 


\section{Resultados e Discussão}

\subsection{Análise dos Campos Afetivos}

O processo de redação na narrativa aplicada (Granato, Corbett \& AielloVaisberg, 2011) evidenciou um mergulho no passado e a identificação da história do personagem com a história de vida dos participantes frente ao alcoolismo. Após a leitura de cada um dos textos produzidos pelos participantes, além das entrevistas pós-narrativas, foram definidos campos de sentido afetivo emocionais, que subjazem às narrativas e suas significações, isto é, mostram como os participantes deixaram emergir a maneira singular de cada um lidar com o tema proposto. Os campos foram nomeados de acordo com os elementos interpretados como latentes nas narrativas dos participantes, em que se procurou compreender os desejos, angústias, faltas e transferências verificadas nos discursos. As falas dos participantes, assim como os trechos de suas narrativas, foram escritas conforme suas redações e transcrições das entrevistas, sem correção gramatical.

\subsubsection{Campo afetivo: A cura no AA vem pela fala, e não com médicos ou remédios. (Participante O.) \\ O campo refere-se à importância da fala e o medo da solidão. O participante}

utiliza-se de metáfora para descrever fases do alcoolismo:

O alcoólatra passa por três fases: a do macaco, quando bebe e tudo é divertido e tudo é alegria!... A do leão, quando dá prejuízo financeiro para família, deixando de comprar o que precisa na casa para pagar dívida dos botecos [...]. E a fase do porco: quando o alcoólatra bebe, agride, xinga, grita com a esposa e no dia seguinte acorda arrependido, com uma ressaca desgraçada e passa de cabeça baixa diante dos vizinhos. (Participante O.)

Para ele, o alcoolismo é incurável e falar sobre a doença nos encontros com iguais torna menos angustiante e doloroso a consciência sobre ela. A troca de relatos entre eles no grupo funciona como terapia. A repetição em relação às histórias e fatos também configura a terapia como função no grupo.

Segundo Gianesi (2005), na psicanálise a tendência à repetição se apresenta, no inconsciente, relacionada à falta, nesse caso o objeto. A repetição é a referência ao original que não o imita, mas o leva ao novo. O participante O. diz: $o$ único que consegue entrar na vida de um alcoólatra é outro alcoólatra, ou seja, falar a própria língua, falar das experiências vividas repetindo para si e para o grupo. 
Para Freud (1930/1996) a valorização da fala e da narrativa como elemento metodológico é fundamental para o conhecimento das comunicações inconscientes dos pacientes. Foi possível perceber uma configuração de sentir-se só, quando o participante disse que a figura do pai o marcou como sendo um homem severo e áspero nas palavras. Seu pai cobrava dos filhos que todos tivessem emprego, porque se não trabalhassem também não iriam comer. A ideia desse pai não querer alimentar os filhos caso não trabalhassem, nos mostra sua dificuldade de dividir, e uma possível desordem na estrutura familiar.

De acordo com a narrativa do participante, na qual descreve toda a sua trajetória no alcoolismo até a sua libertação, há um fragmento em que ele coloca em dúvida o seu papel como pai, ao dizer que não era merecedor do apoio e do carinho dos seus filhos, por ter sido ausente e ter gasto grande parte das finanças com bebida. A imagem que O. possivelmente tinha do próprio pai se configurou-se como não merecedor do carinho dos próprios filhos. $\mathrm{O}$ participante demonstra medo da solidão. Ele conta que, apesar da dependência queria cuidar financeiramente da família, mesmo sendo precário esse cuidado, para não ficar sozinho e sentir-se abandonado por eles. Winnicott (1990) apresenta uma reflexão sobre a solidão, vista numa perspectiva integradora, como uma conquista do bebê, que se estende pela vida adulta. Segundo ele, ficar só é diferente de ficar isolado, e muitos podem estar sozinhos, sem a presença de alguém, mas mesmo assim não estar só. Por outro lado, pode-se ficar só, mesmo estando na presença de alguém.

\subsubsection{Campo afetivo: Minha mãe abriu as} portas do alcoolismo (Participante $\mathrm{R})$.

Esse campo refere-se aos mecanismos psíquicos utilizados para tentar referenciar a relação da ausência da figura materna com o acolhimento maternal simbólico do AA e reflete, em particular, o participante R., que demonstra muita identificação com sua mãe, principalmente no momento em que ela apresenta sérios problemas de saúde. O participante a culpa por sua dependência do álcool, por ela ter sido alcoolista, ela quem abriu as portas do alcoolismo". Ele também se culpa pela doença da mãe por não poder fazer mais por ela e, com isso, consome mais excessivamente o álcool, para aniquilar essa culpa não queria isso prá mim, mas ao mesmo tempo não entendia porque aquilo acontecia.

Para Dor (1989), tanto na criança como no adulto, a falta do objeto pode manifestar-se como frustração sendo constituída pela reivindicação, com a possibilidade de nenhuma satisfação a ser encontrada. O pai também é apresentado 
como sendo um homem ausente, mas afetuoso. Seus pais deram apoio e ajuda quando o participante necessitou de cuidados em relação à sua dependência, colaboraram em buscar internações e tratamento para ele, mas a relação com a mãe pareceu ser simbiótica ao extremo, a ponto de sua ausência e seu exemplo refletirem diretamente no comportamento do participante. Ele tentou buscar relacionamentos para preencher essa solidão, que não deram certo, por não conseguir sustentar vínculos. Hoje, encontra-se interditado judicialmente pelos filhos e não recebe a visita de nenhum deles. Seu único apoio afetivo parece estar nos encontros do AA. O grupo torna-se potencial no intermédio da relação entre pares e as "trocas de informações, espaço de reflexões, processos identificatórios, experiências emocionais verdadeiras com potencial corretivo, tudo aí se dá" (Mello Filho, 2001, p. 242).

Para o participante, o AA teve uma melhor resposta ao tratamento do sintoma. Disse que precisou perceber que sua arrogância não o deixava tratar-se, perdeu muita coisa para entender o que estava acontecendo e buscar ajuda, quando compreendi sobre a minha arrogância, minha prepotência e tudo que havia perdido materialmente, espiritualmente $e$ moralmente.
Para a psicanálise, a leitura dessa arrogância pode ser compreendida como narcisismo, tão evidente nos alcoolistas pois, em termos sociais e culturais, o álcool traz, muitas vezes, a ideia de status, poder e pessoa bem-sucedida (Stacechen \& Bento, 2008), num cenário atual que promove a superficialidade, as aparências, a procura de satisfação, e nem tanto os valores e interioridade da pessoa, aquilo que realmente pode dar sentido às suas vidas.

\subsubsection{Campo afetivo: Eu era rejeitado} mesmo quando não bebia (Participante $\mathrm{L})$.

Este campo contempla as buscas referentes à relação com o outro, nesse caso a relação entre o participante e seu pai. Há um incômodo significativo do participante pela figura paterna e o papel de seu pai em sua vida. Conforme a narrativa e a entrevista pós-narrativa, percebeu-se uma necessidade, não só de reconhecimento, por parte de seu pai, mas também de ser olhado como filho, quando diz: eu era rejeitado mesmo quando não bebia. Podemos pensar que seu pai pudesse ter um ideal de filho, assim como o filho tem um ideal de pai. Provavelmente, experimentou uma fragilidade do ambiente em sua constituição subjetiva. O participante disse: meu pai tratava mal a minha mãe e a mim, e me sentia muito mal. É nesse contexto de relacionamento triangular que a criança 
vivenciará as dificuldades e os ganhos para a sua construção na experiência humana.

Segundo Winnicott (1990), o bom desenvolvimento emocional da criança para relacionamentos interpessoais necessita um ambiente familiar saudável, bem constituído e vivenciar os mais variados aspectos dessa relação triangular. $\mathrm{O}$ participante parece ter o álcool como objeto, que preencha uma possível falta, com efeito totalitário quando a falta inicial for importante. De modo que o encantamento pelo objeto, no caso o álcool, se esgota, percebe-se a angústia para reencontrar o caos inicial vivido (Campos, 2011). Assim, o objeto torna-se coisa em si, como estratégia de defesa perante a uma ameaça de aniquilamento do sujeito. O próprio participante amplia esse olhar de não considerar só o álcool como objeto de preenchimento de uma possível falta: tive sim prejuízo mesmo que não fisicamente, tive uma ausência muito grande do meu teto [...] mesmo morando juntos, estávamos separados. Atualmente não converso com meu pai, faz sete ou oito meses, não posso falar que é só pelo uso do álcool, mas pelo gênio de um e do outro, mágoas que ele tem [...] tem muito ciúmes, são teorias que a minha família e psicólogo me falaram.

3.1.4 Campo afetivo: É que o pobre vomita no chão e o rico vomita no tapete persa. (Participante G.)
A partir das informações adquiridas com o participante, chamou à atenção sua necessidade em contextualizar a sua história de vida ligada a bens materiais: fui uma pessoa criada para dar certo, meus pais me deram tudo do bom na possibilidade que eles tinham. Tive bons estudos, bons empregos, consegui criar minha família com três filhos e minha esposa nunca precisou trabalhar, conseguia dar conta das despesas. Sente-se culpado pelos prejuízos financeiros: trabalhava na capital, tinha um cargo de confiança $e$ ações da empresa em euros, era muito dinheiro, gastei a maior parte do dinheiro, andei metade do Brasil, enquanto passava o cartão no caixa eletrônico e saia dinheiro estava bom. E a bebida alcoólica foi colocada por ele como objeto que também trouxe benefícios: dentro da minha profissão fechei muitos negócios em bar e restaurante chique, fechei muitos negócios regados a pinga e uísque de qualidade.

Stacechen e Bento (2008) escrevem que, em termos sociais e culturais, o álcool traz, muitas vezes, a ideia de status, poder, sucesso, comemorar ação de feitos. Isso se encaixa num cenário atual, que promove a superficialidade, as aparências, a procura de satisfação, e nem tanto os valores e interioridade da pessoa, aquilo que realmente pode dar sentido às suas vidas. Está implicado nesse contexto a valorização e a exaltação do eu, um modo narcisista de 
subjetividade. Parece-nos que o prazer do sujeito da atualidade se reduz ao investimento excessivo narcísico.

Quando o participante diz que foi uma pessoa criada pelos pais para dar certo, compara-se aos irmãos, que não têm problemas com álcool (seu irmão mora e trabalha no exterior e sua irmã possui um bom emprego na capital paulista). Evidencia-se angústia e inquietação em relação à sua vida, aos erros que não poderia cometer e à dependência do álcool, levando ao que ele refere: começou atrapalhar meu trabalho, atrapalhou tanto que comecei a bater o carro da empresa, alguns serviços mal feitos e sou extremamente perfeccionista e não gosto de fazer coisa errada. Apesar disso, ele não tinha tomado consciência de que já se tornara um dependente.

Segundo o participante, sua exmulher não via a situação de consumo excessivo do álcool, como um problema: porque eu trabalhava, ia aos cultos com ela, tinha bons carros, tinha casa, tinha um salário bom e tinha responsabilidade com a família. É sabido que existem muitas resistências do sujeito em admitir a dependência do álcool. Para a maioria, admitir ser alcoolista traz imediatamente sentimentos de vergonha, medo, humilhação, reduzida autoestima (Chagas, 2008).
Somente tomou consciência quando percebeu que seus filhos apresentaram problemas emocionais por causa disso [...]. Embora caráter e educação tivessem bastante, mas financeiramente não estão numa situação boa [...]. O pai e o marido que era o provedor falhou. A partir do sofrimento do outro, nesse caso os filhos, foram percebidas as consequências devastadoras, não apenas financeiras, na vida deles e do participante. Hoje, o participante vive separado e mora em um bairro da periferia, no interior de São Paulo, onde foi possível alugar um chalé, o bairro é pobre e não gasta muito: o dinheiro dava para manter sem trabalhar, fazia pequenos "bicos" de pequenas manutenções residenciais e recebia pequenos valores: $e$ me afundava no bar que tinha no bairro, minha vida foi assim, ganhava um dinheiro e ia gastar lá. Sua vizinha percebendo o sofrimento do participante: "oferecia um pratinho de comida e punha na porta, batia e saía. Não aceita essa nova condição de vida porque, primeiro não era para eu estar nesse lugar, jamais iria morar na periferia porque eu era e sempre fui um cara orgulhoso, tinha um poder aquisitivo bome tive bons estudos, não era prá eu estar lá. Foi possível compreender, em sua fala, uma pobreza de relações e de troca entre os membros da família dos personagens da narrativa. 
Parece que a pobreza de recursos para enfrentar a realidade permeou sua própria experiência de vida quando diz: fiquei cinco anos de página em branco na minha vida, onde ocorreu a ruptura do meu casamento. Apresentou um contexto de vazio, de nada, de pobreza, não apenas de bens materiais, mas do repertório do ego para dar conta do que se apresentava em sua realidade, ocupando este vazio com o álcool. A tendência à repetição se apresenta no inconsciente, relacionada à falta; por meio da repetição, o sujeito tende a controlar a ausência. É próprio da repetição o fracasso da tentativa de reencontrar o perdido (Gianesi, 2005).

\subsubsection{Campo afetivo: Eu não cheguei tão} pior, só que eu não aguentava tudo aquilo que eu aguentava! (Participante B.)

Este campo refere-se à não aceitação da dependência do álcool no início, como o participante se coloca diante da dependência, a tomada de consciência, a reparação, e a sua chegada ao grupo Alcoólicos Anônimos. O participante foi criado pelos avós, começou a chamá-los de pai e mãe, e seus pais biológicos acabaram sendo chamados de tios. Em sua infância, já com seus avós, vivenciou situações de ingestão de bebidas alcoólicas por parte deles, chegando ao ponto de ser incluído nelas: ofereciam o resto da bebida que ficava no copo.

Assim, o álcool foi se estabelecendo em sua vida a partir do ambiente fornecido por esses avós, ambiente que nos leva a pensar como precário em relação a investimento no outro, responsabilidade e cuidado com a criança (Winnicott, 1990). Seu primeiro com o álcool foi aos 13 anos de idade, descrito como uma experiência que me marcou muito [...]. Meus avós estavam comemorando bodas de ouro, eu não vi a festa, quando a festa começou eu estava bêbado e quando eu acordei já estava terminando, já não tinha quase ninguém na festa. O participante se identifica com a juventude do personagem da narrativa, e se coloca junto a ele, ao decidir pelo uso do álcool.

Ele chegou a afirmar que, como o personagem, também sairia para beber e tomaria a mesma atitude de namorar e sair sozinho para festas. Descreveu a adolescência como uma fase de experimentação, e disse que com ele não foi diferente, decidiu por experimentar a bebida alcoólica. Reitera que o uso de drogas traz a sensação de "prazer", e quem as usa sente-se satisfeito. Num ato imaginativo de idealizar um objeto de consumo, no caso o álcool, não importa, se ele corresponde ao real ou ilusório; o que importa é a idealização em si mesma 
(Stacechen \& Bento, 2008). Ou seja, o prazer não é oriundo da experimentação do devaneio, da imaginação.

Segundo Galvão (2001), o momento desejado com o encontro do objeto perdido apresenta uma situação de plenitude, onde nada falta, como um retorno inconsciente de prazer primitivo com a mãe. Porém, o malestar da realidade reaparece, e com ele, a necessidade por mais álcool, formando um ciclo. O participante também relaciona o álcool com a violência: quando cheguei em casa alcoolizado, bati na minha esposa que estava grávida de oito meses do terceiro filho. Puxei pelo cabelo e aquilo marcou muito. Tinha sido uma fase do álcool e foi uma das piores. $\mathrm{O}$ dependente perde parte do julgamento, do pensamento e senso crítico das situações vivenciadas, o que se reflete em ações desordenadas e agressivas (Chagas, 2008).

Ao tomar consciência da sua dependência, o participante considera como alcoolista aquele que não tiver domínio da bebida. Lembra: tinha me casado com a intenção de ser um bom marido; afirmou que sua esposa dizia que ele havia prometido no casamento que seria um bom marido. Minha mãe e minha esposa me tinham como um herói porque era um homem esforçado e dava conta. Mas sua dependência influenciava negativamente essa conduta de herói. Sua mãe lamentava: porque você está afundando desse jeito. Os filhos ainda pequenos já vivenciavam e sofriam as consequências da dependência do participante:

Saia de manhã de casa para buscar leite aos domingos e levava meus dois filhos pequenos numa bicicleta, pedalando por três quilômetros e meus filhos não queriam entrar no bar. Eu dizia que ia beber só uma, e entrava e eu dava um docinho prá ficar agradando as crianças, mas eles começavam a chorar porque queriam ir embora [...]. Chegava em casa uma hora da tarde, bêbado, caindo.

Reitera: comecei a perceber que estava indo além da conta do que eu queria, só que eu não sabia que era alcoólatra [...]. Eu não quero beber, por que Deus deixa eu beber? Eu achava que Deus estava sendo meu garçom! Tomou ciência da sua dependência e começou a fazer reparações em sua vida e em seu ambiente de convívio. Por decisão própria parou de beber, deu início às reuniões de Alcoólicos Anônimos, entrei no AA na hora certa, pois percebeu o início dos prejuízos causados pela dependência e julga necessário dar continuidade às reuniões do grupo, porque "precisa". Esta palavra, 'precisa' referida pelo participante, significa que, no grupo, há identificação das histórias, dos relatos, dos processos desencadeados pelo álcool, 
do sofrimento, com uma possível identificação com os membros do grupo. Parece não haver uma percepção da singularidade dos frequentadores, valorizando o geral, os iguais, o grupo.

Por fim, percebe-se uma ambivalência de sentimentos vividos pelo participante, pois, ao mesmo tempo que se incomoda em ser dependente do álcool, sente-se também aliviado em poder recorrer ao AA, como possível recuperação, por ter tido a chance de sair, ao menos em parte, do sofrimento da sua dependência. Atualmente faz tentativas de reparos, obviamente carregadas de culpa, à vida dos filhos e de sua esposa: hoje tenho pensado e agido diferente porque quando preciso comprar algo no supermercado para os meus filhos saio e penso em voltar logo para trazer o que fui buscar.

\subsubsection{Campo afetivo: Não tinha minha mãe,} não tinha minha família e não tinha ninguém! (Participante A)

Este campo levantou questões relacionadas à ausência da mãe e ao sofrimento causado pelo sintoma alcoolismo. A falta do objeto, tanto na criança como no adulto, pode manifestar-se sob três formas específicas, a frustração, a privação e a castração (Dor, 1989). Nesse caso, foi percebida essa falta do objeto amado a partir das descrições trazidas pelo participante: os motivos que me levavam a beber normalmente era perda, ou de não conseguir aquilo que eи queria. As perdas marcaram a minha vida. A primeira perda foi minha namorada, fiquei muito tempo traumatizado [...]. A partir dessa situação fui procurar outras pessoas e cada vez que eu procurava novas pessoas tinha bebida no meio.

Segundo Dor (1989) a frustração se constitui pela reivindicação, com a possibilidade de nenhuma satisfação ser encontrada. Na frustração, a falta é um dano imaginário. Por outro lado, o objeto da frustração é totalmente real. Conforme descrito por Queiroz (2005), a mãe é convocada permanentemente a ser o espelho da criança, pois a criança irá se ver no olhar de sua mãe, confrontando-se com seu desejo. É no olhar da mãe que a criança reconhece sua própria imagem, a partir da imagem do Outro. É essencial o reconhecimento da mãe para a criança perceber seu corpo. Mesmo que houvesse facilitação da mãe nesse processo de identificação, nas fases seguintes da infância do participante, conforme fragmentos de suas falas, a mãe se ausenta de várias formas.

O participante nomeia os motivos que o levavam a beber, a saber, a perda e o fato de não conseguir aquilo que desejava. Esses fragmentos nos ajudam a pensar melhor no dinamismo entre mãe e filho: 
Lembro que minha família se reunia aos finais de semana para jogar baralho na casa de meus pais. Na época tinha 7 anos e ficava com os adultos, quando um faltava eu entrava porque tinha aprendido a jogar também. Eles bebiam cerveja e às vezes pinga e eu acabava tomando um golinho do que eles bebiam [...] meus tios jogavam futebol de várzea aos domingos e me convidavam para assistir os jogos e durante o jogo eles paravam para beber cerveja ou pinga, e me davam um copo de cerveja e a coisa foi indo [...] quando era mais novo ia buscar meu pai, que estava embriagado, aos sábados tarde da noite no jogo de bocha com os amigos. Eu ia sozinho de bicicleta buscá-lo. Minha mãe ficava desesperada, não dormia e ficava preocupada, tanto é que toda essa preocupação com meu pai passou prá mim, porque quando eu saía à noite, ela não dormia.

Quando ele tinha 20 anos de idade, sua mãe adoeceu, desenvolveu câncer no seio, fez mastectomia, e logo em seguida, apareceram metástases nos ossos, vindo a falecer. Winnicott (1975) define que a função dos objetos transicionais é simbolizar a falta da mãe, para livrar-se de sua dependência, enquanto não se pode ter uma mãe suficientemente boa adequadamente introjetada. Na tentativa do preenchimento da perda real e simbólica, e na frustração de não realizar seus desejos, o alcoolismo surge como sintoma possível. As respostas dadas a esse sintoma foram percebidas em particular na sua vida adulta:

Era um dependente quando comecei a beber continuamente a partir dos 23 anos, bebia todos os dias praticamente porque tinha separado da primeira namorada, estava desempregado, cursava a faculdade, estava sem dinheiro para pagar, tinha que me preocupar em arrumar trabalho porque estava desempregado [...] conheci minha atual esposa em um camping, os dois bêbados praticamente, ela também bebia muito. O início do nosso namoro começou bebendo, passamos alguns meses do nosso relacionamento bebendo, nos casamos bebendo até o nascimento do nosso filho, a gente estava bebendo juntos, mas ela parou de beber [...] aos 40 anos, continuei a beber não era só dia de semana, mas todos os finais de semana também porque tinha o dia livre e morava do lado de um bar [...] quando eu acordei em 2010, eu percebi que não conseguia parar de beber, eram três horas da manhã e ainda estava bebendo porque tinha começado no início da noite, todos os 
dias [...] eu já havia perdido tudo, contrai dívidas que mantenho até hoje e chegou num ponto crítico que não tinha mais saída e tentei me internar.

Pode-se compreender que, uma primeira função do sintoma seja o preenchimento do vazio gerado pela quebra do espelho e a segunda, uma possibilidade infinita de adquirir o gozo pela repetição. Há um encontro da falta com algo que preenche essa falta, e o objeto terá um efeito totalitário quando a falta inicial for importante. Quando o encantamento pelo objeto álcool se esgotar, há um medo de reencontrar o caos inicial, constituindo o estado de dependência (Santos, Queiroz \& Lins, 2007).

\subsubsection{Campo afetivo: Já sabia que tinha um envolvimento diferente com a bebida (Participante T)}

Neste campo foram levantadas questões do participante referentes à sua relação com o álcool, juventude, prazer e gozo, experiência de liberdade das pulsões e desejos. Nota-se uma associação entre juventude e álcool: a ligação da juventude com o álcool te dá uma visão de mundo florido e alegre e supera todas essas visões da vida sem o álcool. Ou seja, parece sair da lucidez, para submergir nos efeitos da bebida alivia possíveis angústias reais, dando lhe um sentimento de euforia imaginária, mas não vivida na realidade.

Segundo Stacechen e Bento (2008), o desejo, mesmo não sendo realizado, sugere uma felicidade imediata. Logo após, surge um novo desejo para ser atendido, e a repetição dessa busca por ele parece deixar um vazio no sujeito, quando ele se percebe no ambiente real. Em suas experiências iniciais com o álcool, o participante destaca: tinha 10 anos e eu era o primeiro neto, $e$ servia o uísque a todos e tomava o meu escondido debaixo das escadas para ninguém ver e depois eu ia pedir um golinho pra eles, era tão boa a sensação. Já quando escreveu a narrativa, expôs: neste momento algo mágico aconteceu, uma sensação de liberdade e euforia apareceu. Deu-se a largada para uma nova vida, em que o bemestar que não conhecia até então permitiria que algo de diferente em sua vida pudesse ocorrer. Isto nos leva a pensar que uma criança de 10 anos de idade já percebe a satisfação e bem-estar após ingerir bebidas alcoólicas, isto é, a falta que pode ter sido preenchida com o objeto álcool, de forma a devolver o prazer imediato (era tão boa a sensação!). Aos 17 anos de idade percebeu que tinha alguma relação diferente com o álcool. Nas suas palavras: percebi que era alcoólatra, oи que eu viria a ser.

Possivelmente, como defesa em não querer se assumir dependente, preferiu "florear" a sua história de vida e distorcer 
para não ser "crucificado" naquela época. Esse simbolismo dado pelo participante a uma juventude ativa e "feliz" parece esconder angústias ainda não externalizadas, pois ao colocar que há distorção da história para não ser “crucificado", nos leva a pensar num desejo de ser ouvido, mas sem efetivação: eu tinha uma relação diferente com o álcool, havia o medo de não saber o que era alcoólatra, porque vai que eu fosse e comecei a desconfiar que poderia ser um alcoólatra. Todo alcoólatra acha que ele não é.

Diante do que foi descrito por ele, é possível fazer uma compreensão do fenômeno aditivo como modelo de fetichismo. Nas adições, em geral, é observada uma fixação exacerbada a um objeto, sendo buscado como única fonte de prazer para o sujeito, tornado uma espécie de objeto-fetiche (Gurfinkel, 2007). Assim, o objeto torna-se coisa em si, como estratégia de defesa perante a uma ameaça de aniquilamento do sujeito. Há um movimento de não aceitação do seu sintoma, utilizando defesas do ego, como a racionalização, para não entrar em contato consigo: é mais fácil e cômodo esconder essa situação [...]. Eu também me escondia muito, eu não participava de muitas situações familiares porque sabia o que ia acontecer quando eu chegava. Existem várias resistências do sujeito em admitir a dependência do álcool, ligadas a questões culturais, morais, religiosas, mas principalmente às questões da própria vida da pessoa. Para a maioria, admitir ser alcoolista traz imediatamente sentimentos de inferioridade (Chagas, 2008).

Ao pensar sobre o sintoma alcoolismo, observa-se a ideia de álcool como objeto, pois o participante define os efeitos do álcool como bem-estar:

Alcoólatra para ter que parar de sofrer de alcoolismo, ele tem que parar de beber. E parar de beber não é fácil para quem é alcoólatra [...] o bemestar proporcionado pelo álcool tem um preço claro: $O$ mesmo nível de conforto só se mantém a cada dia, se houver uma compensação e esta, com o tempo, cobra em doses, maiores a cada vez e menores na distância entre cada uma delas.

A ingestão do álcool leva a uma situação de prazer, na qual os momentos dolorosos e difíceis de serem lidados se limitam e, até o fim do efeito, desaparecem (Galvão, 2001). O dependente de álcool possivelmente encontra na bebida o objeto que preenche essa falta, tendo um gozo pleno até o fim do efeito da substância no organismo. O gozo, para Melman (2000), vem marcado pela fixação oral, reaguçada durante a vida. A fixação nessa situação se apresenta com a representação imaginária 
do gozo por um líquido, com o uso fora do limite, por não reconhecer outro limite a não ser o fisiológico do corpo, no qual parece buscar a satisfação, ou seja, uma forma de descarga para baixar essa tensão ou satisfazer esse prazer (Gianesi, 2005).

Por fim, já em processo de reparação consigo e com o outro, percebeu a necessidade de falar sobre o sintoma do alcoolismo, após ser orientado por uma pessoa que considera importante,

Fale do álcool bebendo ou não, porque você vai conviver com ele para o resto da sua vida [...] falando de álcool para Deus e o mundo, só não fui prá dentro de boteco falar de álcool porque não era apropriado [...] eu me comprometia comigo mesmo, foi o que essa pessoa me ensinou. Se você não compromete com você mesmo, esquece, ninguém vai! E a melhor forma de se comprometer é falar de álcool [...] com o passar dos anos a pessoa aprende a falar sobre o álcool, isso ajuda a não sofrer a mesma obsessão quando bebia.

Dar voz ao discurso traz muito da subjetividade do sujeito e, a partir desse olhar psicanalítico, perceber o lugar da dependência do álcool ocupa nessa subjetividade (Nogueira, 2006).

\subsection{Discussão Geral dos Campos}

De acordo com a riqueza do material coletado, em uma tentativa de aproximação dos dados obtidos, foi possível perceber pontos em comum entre eles, como, a primeira experiência com o álcool realizada na adolescência; os pais ou cuidadores de alguma forma incentivavam os participantes a experimentar o álcool; associação da dependência com algum tipo de perda; reparação como forma de amenizar os prejuízos causados a outras pessoas e a si mesmos; e a identificação com o grupo, em particular com o grupo dos Alcoólicos Anônimos.

\subsubsection{Relação infância/adolescência-álcool}

$\mathrm{Na}$ adolescência, o jovem experimenta mudanças fisiológicas e psicológicas, nas suas percepções em relação a si próprio e aos outros, sendo um período de maior fragilidade egóica, resultando num retorno narcísico para seu mundo interno, com questionamentos na relação com os pais, as instituições e a sociedade. Este retorno narcísico provoca uma série de angústias naturais próprias desse período, como as da identidade pessoal, as depressivas, pela perda da identidade infantil, e até paranoides, devido à luta interna que passa a travar em busca desse novo conhecimento (Freud, 1923/1976a).

A questão identificatória dos filhos com os pais, que vem se desenrolando desde 
cedo com as vivências relativas ao Complexo de Édipo, são retomadas na adolescência, com uma carga emocional muito forte, em soma com todas as modificações hormonais e físicas que a pessoa está passando. A busca de uma profissão, as experiências ligadas à sexualidade e à afetividade, a cobrança social a respeito do futuro, aparecem ao adolescente como desafios que exigem dele medidas urgentes, o que depende de uma base psíquica sólida e das referências do mundo adulto, especialmente as parentais, para se estabelecerem.

Nesse aspecto, o modelo oferecido por pai e mãe pesa muito, pois o adolescente buscará se espelhar nele para se constituir como sujeito autônomo. As dificuldades se agravam quando se trata de situações e relações conflitivas, ou desorganizadas, como acenam a maior parte dos participantes dessa pesquisa: minha primeira experiência com álcool foi aos 10 anos (R.); comecei a ingerir o álcool com 14 ou 15 anos, com bebidas mais suaves $e$ depois comecei a fumar maconha (L.); foi muito cedo, por volta dos 13 anos de idade e tinha sido numa festa de casamento do meu primo (G.); foi com 13 anos de idade, foi uma experiência que me marcou muito também (B.); comecei a beber quando era garoto tinha entre 8 e 10 anos de idade (A.); eu era muito pequeno e de família italiana, era comum ter vinhos com refeições (T.).
Em se tratando especialmente do estabelecimento do alcoolismo e sua relação com o final da infância e adolescência, se o álcool é presença constante na vida dos adultos com os quais a criança-adolescente convive, chegando ao ponto de a bebida lhe ser oferecida ou apresentada como apetecível, é de se supor que ela seja incluída como elemento de busca da pessoa, ou pelo simples prazer de experimentar ou identificar-se com o mundo adulto tão sonhado, ou como um protesto à situação de sofrimento em que vive, repetindo o ciclo vicioso: problemasbebida-problemas (Freud, 1923/1976b).

Quanto à preferência do adolescente pelos seus pares, isso também se constitui como característica da fase, pois representa um desapegar-se da relação quase exclusiva com os pais, sinônimo de independência e autonomia. Ao sair de casa e frequentar a vida social dos adultos, inclusive espaços e ambientes onde o álcool se faz presente, em uma sociedade permissiva e incentivadora da bebida, se tiver uma estruturação egóica boa, o adolescente poderá até experimentar o álcool, ou dele começar a fazer uso por conta da conformidade ao seu grupo, mas as chances da dependência poderão ser menores.

\subsubsection{Relação identificatória dependente- cuidador}


Os participantes relataram de maneira recorrente nas narrativas que foram os seus pais ou cuidadores que, de alguma forma, os incentivaram a experimentar o álcool, ao oferecerem o resto da bebida que sobrava no copo. Nesses contextos, pode-se pensar numa relação de identificação, como já acenamos anteriormente, dos filhos com seus pais. Nessa relação com o outro, o sujeito pode buscar se constituir inconscientemente dos traços identificatórios retirados a partir do outro.

A subjetividade, no seu processo de construção, passa por um momento primitivo, em que a relação dual leva a criança a experimentar a fusão e a confusão de um eu indiferenciado com a mãe, concebida como parte dela. A criança precisa ir ganhando, aos poucos, o seu lugar sobre o outro, de se impor a ele, se não acaba por aniquilar-se. Freud (1921/1996) afirma que a forma mais primitiva de laço se dá na identificação do menino com seu pai. O pai é tomado como seu grande ideal, levando ao Complexo de Édipo, pois a identificação com o pai e suas características visaria à consecução e ao gozo do objeto amado, no caso a mãe.

No processo, chegará o momento em que a castração colocará limites ao desejo do menino, e ele terá que colocar em um segundo plano a figura da mãe, mas não renunciará ao gozo, que poderá ser encontrado de outras formas. Uma delas poderá ser a identificação a alguma característica mais forte do pai, substituindo a forma do gozo. Mas se o Édipo não for bem resolvido, isso também terá seu preço.

Em quase todos os casos trazidos pelos participantes, eles conviveram desde muito cedo com o alcoolismo dos cuidadores masculinos (em alguns pai e mãe bebiam). Minha mãe bebia para sofrer menos (R.); meu pai era um alcoólatra não assumido (A.); $90 \%$ da minha família é alcoólatra porque eu acredito muito que seja algo hereditário passa de pai prá filho. Minha família desde atrás é alcoólatra, minha família tem problema essa é a verdade" (B.). Essa era a característica predominante dos cuidadores, e os filhos acabam por se identificar com ela, possivelmente por verem nela uma forma, ainda que contraditória, de reconhecimento e de ter algum poder. No álcool, está o pai do gozo e não o pai da lei. A dependência adquirida muito cedo nos leva a pensar em dificuldades na resolução do Édipo e para encontrar harmonia entre como viver sua busca de prazer e sua realidade, que são bem diferentes (Dor, 1989).

\subsubsection{O alcoolismo como compensação de perdas}

Os participantes descreveram um sentimento de perda, relacionando-o conscientemente à dependência. No ambiente suficientemente bom o bebê 
começa a experimentar o sentimento de confiança em um mundo acolhedor (ou não), começa a existir como sujeito, domina os instintos, vivencia dificuldades dentro desse ambiente para o seu desenvolvimento e a constituição do seu eu (Winnicott, 1990). A mãe (ou quem dele cuida) irá frustrá-lo aos poucos, deixando de atender às suas necessidades, quando ele já for capaz de acolher e integrar essas lacunas e o bebê substitui essa perda com algum objeto externo, um objeto transicional, que esteja seguramente disponível a ele (Winnicott, 1975).

No caso da dependência alcoólica as perdas foram preenchidas pelo objetoálcool, colocado no lugar dos objetos transicionais A dificuldade de abandono do objeto transicional pode levar a uma fetichização de algum objeto, ou necessidade compulsiva de algo que ocupe o vazio impreenchível (Stacechen \& Bento, 2008). Ao preencher essa falta com a bebida possivelmente marcada pela fixação oral, vem a sensação de prazer e do gozo. $\mathrm{Na}$ busca pelo gozo constante percebe-se o movimento da repetição. A partir dessa repetição e da plenitude que o álcool disponibiliza ao sujeito que fez uso, há um encontro com o objeto perdido ou faltante, pois é nesse momento que nada falta a ele e, consequentemente, o faz retornar ao prazer primitivo com a mãe (Galvão, 2001).
Para Gurfinkel (2007) esse objeto pode ser investido com ênfase pelo sujeito dependente como sendo única fonte de prazer e também pode tornar-se uma espécie de objeto-fetiche, no caso, a bebida: Os motivos que me levavam a beber normalmente era perda ou de não conseguir aquilo que eu queria (A.); uma namorada que tive, ela foi meu primeiro amor (R.); foi a convivência familiar, a ausência do meu pai e com a minha irmã (L.); não me vi na história porque não fui criado pelos meus pais (B.).

\subsubsection{O sujeito dependente e a necessidade de reparação}

Os participantes realizam a reparação a pessoas do seu meio, como forma de amenizar os prejuízos causados na vida delas. Os participantes tentaram, ou estão tentando melhorar e mudar a forma de se relacionar com seus familiares e amigos, preocupando-se em fazer a reparação, como um item dos doze passos sugeridos pelo AA, para que a pessoa dependente possa reavaliar os prejuízos causados pela dependência: Procurei a família através da programação do AA na parte reparação, tentei fazer tudo certinho porque sou meio CDF e vou fazer essa receita aqui (12 passos do AA)... Entendi que a reparação é minha, não posso fazer pelo meu filho e 
pedir desculpas e querer que ele aceite a minha reparação (G.).

Quando o dependente consegue dar o primeiro passo em sua reparação, esta é compartilhada com os membros do grupo, mesmo com tentativas fracassadas. A reparação feita por eles tem, como outra face, a culpa pelas condutas erradas com a família, por não terem bebido apenas um gole como pretendiam, por não terem convivido com os filhos sem estarem embriagados, por terem agredido a esposa, por terem preferido beber do que levar o alimento que o filho precisava, enfim, são inúmeros os discursos trazidos pelos participantes que envolvem o sentimento de culpa: Acredito que no meu caso com a minha mãe e meu pai eu me sentia culpado por tudo e tentava me destruir e fugir da realidade $(\mathrm{O})$; bati na minha esposa que estava grávida de oito meses do terceiro filho, puxei pelo cabelo e aquilo marcou muito (B.).

A questão da culpa do sujeito deve ser examinada a partir de sua singularidade, e não apenas de modo padronizado ou generalizado. Para Winnicott (2000) o sentimento de culpa é percebido na iniciativa que o bebê tem em querer reparar os danos com alguma coisa boa para a mãe, o "buraco no seio ou no corpo, criado imaginativamente no momento instintual original" (p. 365).
A partir do contato com os participantes, foi possível perceber sua necessidade de modificar seus alvos de satisfação pulsional, e de reparar possíveis danos reais decorrentes dessas descargas, motivados pelo AA, que os ajuda a perceber oportunidades adequadas para esse trabalho construtivo em suas vidas. Eles conseguem partilhar o sentimento de culpa com o grupo e começam a caminhar na estrada da reparação; conversava com membros do $A A$ dizendo que tinha bebido no dia anterior as reuniões, os membros me dava tapinhas nas minhas costas e pedia para voltar no dia seguinte (T.). Se houver falhas na oportunidade de reparação, isso os coloca às voltas com o sentimento de culpa intolerável, podendo haver recaídas.

Segundo Winnicott (1983), o sentimento de culpa é ponto existente para cada sujeito individualmente e, mesmo formando um grupo por identificação, isso não torna possível generalizar que $\mathrm{o}$ sentimento seja igual para todos, pois cada um tem uma experiência e maneira próprias de lidar com ele. Há uma preocupação por parte dos participantes em reaver fatos e situações que, por conta da dependência, resultaram em prejuízos em suas vidas e na vida de terceiros: voltei ao grupo todos os outros dias com medo de perder a minha família, medo de morrer porque praticamente estava com o pé na cova (A.). 
Nos casos de dependência, a necessidade de reparação, vivida pelo sujeito dependente, nem sempre encontra na família, ou nos que fazem parte de sua vida, um ambiente sustentador para que o ato se dê com seriedade e comprometimento. Pode ocorrer, ainda, que a necessidade reparadora seja abraçada apenas como uma obrigação externa, imposta como condição para permanecer no grupo do AA, e não como um movimento consciente e refletido do sujeito, que parte de dentro para fora, isso é, de sua decisão livre e desejante da reparação.

\subsubsection{Identificação com o grupo AA}

O grupo do AA figura na vida dos sujeitos dependentes como o ambiente onde eles têm a oportunidade de ser acolhidos, olhados e escutados, mesmo que seja com um enfoque social, já que não é seu propósito abrir espaço para uma escuta psicológica, o que já seria intuito de um grupo psicanalítico. Grupos como o AA, nos quais os participantes se identificam pelo fato de falar e conviver com pares, funcionam como um facilitador terapêutico para a exploração dos sintomas, embora não haja um enfoque de interpretação desses sintomas e sim de descarga, como definido no grupo, em que o intuito é de falar sobre o alcoolismo.

No AA existe um propósito, que é a recuperação por meio dos doze passos, da partilha do discurso e das experiências vivenciadas. Percebe-se um laço mútuo existente entre eles, apontando para uma natureza de identificação, como importante qualidade emocional em comum. Portanto, cada membro que se apresenta com o ideal de eu fragilizado, se depara com os outros membros do grupo e, por sugestão, se percebe identificado com o mesmo (Freud, 1921/1976). Outro propósito do grupo é resgatar o sujeito dependente dos rótulos nos quais foi imerso pela sociedade (como 'bêbado', 'cachaceiro').

O sujeito dependente, pelo olhar do senso comum, é marginalizado diante da sociedade, é estigmatizado. O grupo AA dá a oportunidade de o sujeito dependente poder ressurgir desse montante de rotulações e atribuições negativas em relação a si mesmo: Quando um alcoólatra está muito bêbado pode ter certeza que esse cara está sofrendo (T.). Ele, portanto, recorre ao grupo em busca de oportunidades para se refazer em todos os sentidos.

\section{Considerações Finais}

Nesta pesquisa, foi possível refletir como cada sujeito dependente possui histórias totalmente singulares quanto ao início e permanência no uso do álcool. O adentrar na dependência do álcool foi para alguns, o preenchimento de uma ausência, para outros, do narcisismo, da intolerância, 
da ansiedade, do medo e muitas outras angústias.

Outro aspecto significativo trazido pelos participantes refere-se à importância da fala do sujeito e seu poder curativo. Foi recorrente o discurso dos participantes de que falar, relatar o vivido, partilhar as experiências, a própria repetição do discurso, têm forte efeito, não somente de alívio, mas de organização emocional das vivências conflitivas. Por outro lado, ouvir o testemunho dos 'irmãos' do grupo, provoca no alcoolista a identificação e sucessivas reedições das experiências pessoais, e consequente tomada de consciência e tentativas de mudanças de vida: valorização da família e do trabalho, resgate da autoestima, convocação ao perdão de si mesmo, etc.

Por meio das narrativas e das entrevistas com os participantes e de sua análise foi possível levantar um número significativo dos campos afetivos dos participantes, viabilizando o objetivo de investigar a relação entre dependência química e história de vida nos sujeitos dependentes de álcool. Elementos relevantes surgiram, a relação familiar antes e após o álcool, o processo de dar sentido à própria doença, a tomada de consciência na busca por tratamentos, os efeitos negativos causados à família, etc.

Por ser o alcoolismo um fenômeno tão amplo e complexo, há espaço para inúmeras pesquisas que possam desdobrar os temas relativos a ele, o que contribuirá imensamente para o alargamento da visão do sujeito dependente e toda a sua problemática. Ao pensar na função terapêutica e social do AA, novos olhares podem ser promovidos aos discursos ali promovidos e que assim permitam novos caminhos de reflexão à sociedade, aos profissionais da saúde mental, aos grupos de apoio social como o AA, e a eles próprios, os sujeitos dependentes, na compreensão do que lhes acomete e possíveis caminhos de superação pela fala.

\section{Referências Bibliográficas}

Campos, E.P (2011). Holding: um conceito winnicottiano. In Campos, E.P. Quem cuida do cuidador: uma proposta para os profissionais da saúde. (4 ${ }^{\mathrm{a}}$. Ed). Petrópolis, RJ: Vozes.

Chagas, M.T.T. (2008). O alcoolismo e o grupo de Alcoólicos Anônimos: O conhecimento de alcoolistas. Cadernos Brasileiros de Saúde Mental, 2(4-5), 190-215.

Dor, J. (1989). Introdução à leitura de Lacan: O inconsciente estruturado como linguagem. São Paulo: Artmed. 
Freud, S. (1921/1976). O ego e o Id e outros trabalhos. In Freud, S. Obras Completas. Rio de Janeiro: Imago.

Freud, S. (1923/1976a). Psicologia de grupo e a análise do ego. In Freud, S. Obras Completas. Rio de Janeiro: Imago.

Freud, S. (1923/1976b). Dois verbetes de Enciclopédia. In Freud, S. Obras Completas. Rio de Janeiro: Imago.

Freud, S. (1930/1997). O mal-estar na civilização. In Freud, S. Obras Completas. Rio de Janeiro: Imago.

Galvão, V.L.B.S. (2001) Gozo e alcoolismo. Cogito, 3, 91-93. Recuperado em 15/10/2017 em: http://pepsic.bvsalud.org/scielo.php?pid=S151994792001000100011\&script=sci_arttext.

Gianesi, A.P.L. (2005). A toxicomania e o sujeito da psicanálise. Psychê, ano IX(15), 125-138. Recuperado em 24/03/2016 em: http://pepsic.bvsalud.org/pdf/psyche/v9n15/v9n15a10.pdf.

Gigliotti, A. \& Bessa, M.A. (2004). Síndrome de Dependência do Álcool: Critérios diagnósticos. Revista Brasileira de Psiquiatria, 26, 11-13. Recuperado em 24/03/2016 em: http://www.scielo.br/pdf/rbp/v26s1/a04v26s1.pdf.

Granato, T.M.M.; Corbett, E. \& Aiello-Vaisberg, T.M.J. (2011). Narrativa interativa e psicanálise. Psicologia em Estudo, 16(1), 157-163. Recuperado em 15/10/2017 em http://www.scielo.br/pdf/pe/v16n1/a18v16n1.pdf.

Gurfinkel, D. (2007). Adições: da perversão da pulsão à patologia dos objetos transicionais. Psyche, 11(20), 13-28. Recuperado em 20/08/2017 em: http://pepsic.bvsalud.org/scielo.php?script=sci_pdf\&pid=S141511382007000100002\&ln $\mathrm{g}=\mathrm{pt} \& \mathrm{nrm}=$ iso \&tlng=pt

Mello Filho, J. de M. (2001). O ser e o viver: Uma visão da obra de Winnicott. São Paulo: Casa do psicólogo.

Melman, C. (2000) Alcoolismo, delinquência e toxicomania: uma outra forma de gozar. São Paulo: Escuta.

Ministério da Saúde (2012). Alcoolismo. Brasília. Recuperado em 05/05/2017 em http://www.brasil.gov.br/saude/2012/04/alcoolismo.

Nogueira, C. S. P. (2006). A família na toxicomania. In, Cirino, O.; Medeiros, R. (Orgs.). Álcool e outras drogas: impasses, escolhas e saídas possíveis. (pp. 147-156). Belo Horizonte: Autêntica.

Queiroz, T. C. N. (2005). Do desmame ao sujeito. São Paulo: Casa do Psicólogo, 2005

Reis, T.R. (2007) "Fazer em grupo o que eu não posso fazer sozinho": indivíduo, grupo e identidade social em alcoólicos anônimos. Tese de Doutorado, Programa de Pós- 
Graduação em Serviço Social, UFRJ, Rio de Janeiro, Brasil. Recuperado em 07/07/2017 em

http://www.ets.unc.edu.ar/xxseminario/datos/anteriores/binarios/congresos/reg/slets/slets019-260.pdf.

Ribeiro, C.T. (2009). Que lugar para as drogas no sujeito? Que lugar para o sujeito nas drogas? Uma leitura psicanalítica do fenômeno do uso de drogas na contemporaneidade. Ágora, XII(2), 333-346. Recuperado em 24/03/2017 em http://www.scielo.br/pdf/agora/v12n2/v12n2a12.pdf.

Ribeiro, D.A.; Cunha, G.O.D. \& Azarias, L. (2011). Uma análise do programa de recuperação dos alcoólicos anônimos. Conexão Ciência (Online), 6(2), 59-74. Recuperado em 07/07/2017 em https://periodicos.uniformg.edu.br:21011/ojs/index.php/conexaociencia/article/view/88

Santos, A.B.; Queiroz, T.C. \& Lins, L. (2007). O estádio do espelho e suas relações com as toxicomanias. Anais do IX Encontro de Extensão da UFPB-PRAC, João Pessoa, PB. Recuperado em 16/04/2017 em: http://www.prac.ufpb.br/anais/IXEnex/extensao/documentos/anais/6.SAUDE/6CCSDMI PEX01.pdf.

Stacechen, L.F. \& Bento, V.E.S. (2008). Consumo excessivo e adição na pós-modernidade: Uma interpretação psicanalítica. Fractal: Revista de Psicologia, 20(2), 421-436. Recuperado em 23/03/2017 em: http://www.scielo.br/pdf/fractal/v20n2/09.pdf.

Winnicott, D.W. (1975). O brincar e a realidade. Rio de Janeiro: Imago.

Winnicott, D.W. (1983). O ambiente e os processos de maturação. São Paulo: Artmed.

Winnicott, D.W. (1990). A capacidade de estar só. São Paulo: Artmed.

Winnicott, D.W. (2000). Da pediatria à psicanálise. Rio de Janeiro: Imago.

\section{Os autores:}

Márcio Kobayashi é psicólogo, pela UNIFAAT Centro Universitário, atua como psicólogo clínico no Espaço Camila Ferreira e-mail: mkx.psico@gmail.com

Marjorie C. R. Silva é psicóloga (USF), Mestre e Doutora em Avaliação Psicológica (USF), e-mail: silvamarjorie@yahoo.com.br

Geraldo A. Fiamenghi-Jr é psicólogo (PUC-Campinas), Mestre em Educação (UNICAMP), PhD em Psicologia (The University of Edinburgh, e-mail: geraldoafj@ gmail.com

Recebido em: 23/02/2018

Aprovado em: 28/12/2018 